\title{
Interspecies transfer of vancomycin, erythromycin and tetracycline resistance among Enterococcus species recovered from agrarian sources
}

\author{
M. Conwell, V. Daniels, P. J. Naughton* and J. S. G. Dooley
}

\begin{abstract}
Background: Enterococci are now well recognised for their ability to transfer antibiotic resistance and for their association with nosocomial infections, but less is known regarding their relevance in the wider environment. Enterococcus faecalis and Enterococcus faecium were isolated from a range of agrarian associated sources (low-flow water, septic tank, poultry litter, high flow water, slurry/soil) and were assessed for latent ability to transfer antimicrobial resistance.

Results: The isolates were tested for phenotypic clumping in the presence of cell-free supernatant from other isolates. Some isolates were identified which demonstrated clumping, indicating that they possessed peptide sex pheromone conjugal machinery. All isolates were also tested for antibiotic resistance phenotypes using both disc diffusion and minimum inhibitory concentration (MIC) assays. These tests revealed that the enterococci demonstrated both phenotypic clumping and antibiotic resistance phenotypes. Based on these selection criteria, the isolates were identified as having the potential for horizontal gene transfer and were used to investigate the transfer of multiple antibiotic resistance phenotypes. Conjugal transfer of antibiotic resistance phenotypes was determined using a solid agar mating method followed by a standard antibiotic selection test resulting in different transfer patterns. An interspecies conjugal transfer of vancomycin resistance from $E$. faecalis to $E$. faecium was identified while the remaining reactions were within the same species. Transfer efficiencies ranging from $2 \times 10^{-1}$ to $2.3 \times 10^{-5}$ were determined based on the reactions of three donor isolates (MF06036, MF0410 and MF06035) and two recipient isolates (MW01105 $5^{\text {Rif }}$ and ST01109 ${ }^{\text {Rif }}$, with the transfer of vancomycin, erythromycin and tetracycline resistance genes.

Conclusions: The conjugation reactions and selection conditions used in this study resulted in a variety of co-transferred resistance phenotypes suggesting the presence of different mobile elements in the set of natural isolates. This study highlights the potential for extensive horizontal gene transfer in a previously neglected reservoir for enterococci.
\end{abstract}

Keywords: Enterococci, Water, Conjugation, Vancomycin resistance, Erythromycin resistance, Tetracycline resistance

\footnotetext{
* Correspondence: pj.naughton@ulster.ac.uk

School of Biomedical Sciences, Ulster University, Cromore Road, Coleraine

BT52 1SA, UK
} International License (http://creativecommons.org/licenses/by/4.0/), which permits unrestricted use, distribution, and reproduction in any medium, provided you give appropriate credit to the original author(s) and the source, provide a link to the Creative Commons license, and indicate if changes were made. The Creative Commons Public Domain Dedication waiver (http://creativecommons.org/publicdomain/zero/1.0/) applies to the data made available in this article, unless otherwise stated. 


\section{Background}

Enterococci are Gram positive, facultative anaerobes and despite not forming spores they are tolerant to a range of environmental conditions [1]. They are ubiquitous inhabitants of the mammalian gastrointestinal tract and are regularly recovered from agrarian ecosystems [2, 3]. Although they do not thrive in water they have been found in surface waters prone to faecal contamination [4] and because of their resistance to salinity they also pose a threat to recreational bathing waters $[5,6]$. Farming practices in Ireland and the United Kingdom currently rely on significant amounts of therapeutic antibiotics and much of the farming effluent drains directly into local water ecosystems $[7,8]$. Recent decades have seen an inexorable rise in antibiotic resistance within enterococci with the emergence of multi-resistance being of particular concern [9]. Hence, water catchments close to farmland have the potential to provide a reservoir of antibiotic resistant enterococci which may pose a threat to human health.

Among the enterococci, a conjugation system based upon pheromone signalling [10] has been implicated in the spread of some of the most important resistance phenotypes although its' influence under environmental conditions remains to be determined. Plasmids that respond to pheromone are common in E. faecalis but less common in E. faecium [9]. These plasmids have also been shown to carry a number of virulence traits including: bacteriocin and cytolysin production, and promote donor-recipient hybrid genomes encoding, for example vancomycin and tetracycline resistance [11]. Enterococci are increasingly presenting as nosocomial pathogens [12] and antibiotic resistance has now become a permanent feature in human infectious diseases. These, pheromone based conjugation systems may also be responsible for the interspecies spread of antibiotic resistance genes amongst staphylococci and enterococci [13]. Previous studies have investigated the presence of antibiotic resistant enterococci in the environment, humans and foodstuffs but this is the first study to focus on enterococci isolated from sites in an agrarian ecosystem.

In the current study enterococci isolated from an agrarian ecosystem were examined to assess their resistance phenotypes and ability to transfer resistance genes by conjugation. These processes identify the catchments as potential reservoirs of antibiotic gene transfer in enterococci. This study set out to demonstrate conjugal transfer of a range of antibiotic resistance genes from enterococci, with multi-resistant strains exhibiting a high level of horizontal gene transfer ability. The aim of this study was to examine the presence of antibiotic resistance genes in water-borne enterococci and determine the phenotypes and genotypes of these isolates with a view towards investigating the transferability of antimicrobial resistance determinants between different species of enterococci.

\section{Methods}

\section{Bacterial strains and reagents}

The E. faecalis and E. faecium used in this study (Table 1), were previously isolated from various sources feeding into river headwaters [14]. Briefly, water was collected and filtered using Millipore Microfil membrane filtration system with $0.45 \mu \mathrm{m}$ filters (Millipore. Hertfordshire, UK). Volumes of 1-50 ml of water samples (diluted in maximum recovery diluent) were filtered and grown on Slanetz and Bartley agar (Oxoid CM0337). Plates were incubated for $4 \mathrm{~h}$ at $37^{\circ} \mathrm{C}$ and $44 \mathrm{~h}$ at $42{ }^{\circ} \mathrm{C}$. Phenotypic identification of isolates as enterococci was carried out using: aesculin hydrolysis, PhenePlate ${ }^{\mathrm{Tu}}$ analysis, gram staining, catalase, PYRase and azide tests [14-16]. All bacteria were maintained on tryptone soy agar (TSA), (Oxoid CM0131) at $4{ }^{\circ} \mathrm{C}$ throughout the experimental time period. All growth conditions and experiments, unless specifically mentioned, were carried out on tryptone soya broth (TSB), (Oxoid CM0129) or TSA at $37{ }^{\circ} \mathrm{C}$. All chemicals and antibiotics used were obtained from Sigma, unless otherwise stated.

\section{Pheromone-induced clumping assay: identification of recipients and donors}

To test if an isolate could be a pheromone producing recipient or a potential donor, cells were grown for $16 \mathrm{~h}$ in $20 \mathrm{ml}$ of TSB. Cells were pelleted by centrifugation $(10,000 \mathrm{RCF})$ for $15 \mathrm{~min}$ at $4{ }^{\circ} \mathrm{C}$. Supernatant was removed and filter sterilised (Millipore 0.22 micron filters) providing a pheromone-enriched broth. The clumping

Table 1 Enterococci (species, source and role in conjugation) in solid surface mating experiments

\begin{tabular}{llll}
\hline Name and Species of agrarian enterococci & \\
\hline Isolate & Species & Source & Potential role $^{a}$ \\
\hline MF06035 & E. Faecalis & Poultry litter & Donor \\
MF06036 & E. Faecalis & Poultry litter & Donor \\
MW01038 & E. Faecalis & Low-flow water & Donor \\
MW02102 & E. Faecalis & Low-flow water & Donor \\
MW03020 & E. Faecalis & Low-flow water & Donor \\
MW03025 & E. Faecalis & Low-flow water & Donor \\
MW03051 & E. Faecalis & Low-flow water & Donor \\
ST02011 & E. Faecalis & High-flow water & Donor \\
MF06019 & E. Faecium & Poultry litter & Donor \\
MF04010 & E. Faecalis & Slurry/soil & Donor \\
MF06030 & E. Faecium & Poultry litter & Donor \\
MW03061 & E. Faecium & low flow water & Donor \\
MW01105 & E. Faecalis & Low-flow water & Recipient \\
MW02043 & E. Faecalis & Low-flow water & Recipient \\
ST01109 & E. Faecium & Septic tank & Recipient \\
\hline Based & &
\end{tabular}

${ }^{\mathrm{a}}$ Based on results of clumping assays 
assay consisted of $500 \mu \mathrm{l}$ pheromone-enriched broth, $500 \mu \mathrm{l}$ fresh TSB, and $20 \mu \mathrm{l}$ of a $16 \mathrm{~h}$ culture added in a $1.5 \mathrm{ml}$ Eppendorf and incubated for four hours $\left(37^{\circ} \mathrm{C}\right.$ rotating at $150 \mathrm{rpm})$. From the final suspension, $20 \mu \mathrm{l}$ was dropped on a glass slide and a coverslip (22 $\mathrm{mm}$ ) was applied. Clumping was determined by eye. Isolates that induced clumping but did not clump in the presence of other supernatants were deemed potential recipients. Isolates that readily clumped were characterised as potential donors. Cells were imaged using phase contrast with 100x (Nikon plan fluor 1.3 oil ph3 DLL) on a Nikon eclipse E400 with a Nikon DS-filc. Images were captured with NIS-elements and image $(\mathrm{NIH})$.

\section{Antibiotic resistance testing}

Enterococci were selected for testing based on positive results from the clumping assay either as a recipient or donor for conjugation. Prior to Minimum inhibitory concentration (MIC) testing, the Kirby-Bauer disc diffusion assay was performed on Mueller-Hinton agar (CM0405) to obtain an estimate of the antibiotic resistance phenotype for each isolate. Briefly, an $18 \mathrm{~h}$ culture of bacteria was re-suspended in phosphate buffered saline. The bacterial suspension was swabbed and spread over the surface of a dried plate. Antibiotic discs (Oxoid) were stamped on the plates using a disc dispenser (Oxoid ST6090). Antibiotics used were ampicillin $(10 \mu \mathrm{g})$, amoxycillin $(25 \mu \mathrm{g})$, cephalothin $(30 \mu \mathrm{g})$, ciprofloxacin $(5 \mu \mathrm{g})$, erythromycin $(30 \mu \mathrm{g})$, gentamicin $(120 \mu \mathrm{g})$, impenem $(10 \mu \mathrm{g})$, linezolid $(10 \mu \mathrm{g})$, neomycin $(30 \mu \mathrm{g})$, oxytetracycline $(30 \mu \mathrm{g})$, quinupristin/dalfopristin $(15 \mu \mathrm{g})$, streptomycin $(25 \mu \mathrm{g})$, trimethoprim $(5 \mu \mathrm{g})$, tetracycline $(30 \mu \mathrm{g})$, teicoplanin $(30 \mu \mathrm{g})$, and vancomycin $(30 \mu \mathrm{g})$. Plates were incubated for $24 \mathrm{~h}$ at $37^{\circ} \mathrm{C}$. Zones were measured (mm) and compared to EUCAST ECOFFs [17]. E. faecalis ATCC 29212 was used as a susceptibility control.

Minimum inhibitory concentration (MIC) assays were carried out on the donors that demonstrated positive antibiotic resistance in the disc diffusion assay. The protocol utilised the broth microdilution protocol described previously [18] with the addition of p-Iodonitrotetrazolium [19], as a colorimetric indicator. Based on the results of the Kirby-Bauer tests the antibiotics used were: vancomycin, erythromycin, streptomycin, tetracycline, trimethoprim, teicoplanin, rifampicin, kanamycin (Gibco), chloramphenicol, and gentamycin. All experiments were carried out using Muller Hinton broth (Oxoid, CM0405) and Iso-Sensitest broth (Oxoid, CM0471). Trimethoprim, resistance/susceptibility was determined in accordance with the EUCAST value database [17].

\section{Creation of rifampicin resistant recipients}

In order to facilitate counter-selection in conjugation experiments, it was necessary to generate rifampicin resistance among the recipient strains. The rifampicin sensitive pheromone producing isolates were grown to late log phase in sub-minimum inhibitory concentrations of the antibiotic. Successive generations were sub-cultured in increasing concentrations of the antibiotic until isolates could grow in $512 \mathrm{mg} / \mathrm{L}$ of rifampicin. All donor isolates in this study were susceptible to rifampicin and all recipients were resistant to rifampicin (denoted as ${ }^{\mathrm{Rif}}$ ).

\section{Determination of transfer efficiency of resistance}

Conjugation experiments were carried out using the solid agar mating method [20]. Briefly, donor and recipient isolates were added together at a ratio of 1:9 onto a non-selective TSA plate and allowed to conjugate for $24 \mathrm{~h}$. The resulting lawn was re-suspended in $1 \mathrm{ml}$ of PBS, serially diluted and spread onto TSA selection plates containing appropriate antibiotic combinations. Plates were incubated for a further $24 \mathrm{~h}$ and transfer efficiencies were calculated (number of transconjugants per donor). Selection plates were comprised of TSA with rifampicin $(100 \mu \mathrm{g} / \mathrm{ml})$ and either vancomycin $(10 \mu \mathrm{g} / \mathrm{ml})$; erythromycin $(50 \mu \mathrm{g} / \mathrm{ml})$; tetracycline $(16 \mu \mathrm{g} / \mathrm{ml})$; or kanamycin $(512 \mu \mathrm{g} / \mathrm{ml})$. Antibiotic free TSA was used as a control. All conjugation reactions were performed at $37^{\circ} \mathrm{C}$.

\section{Detection of antibiotic resistance genes in the transconjugants and their donors}

Resistance genes were detected using colony PCR [21]. Two hundred ng template DNA (in $1 \mu \mathrm{l}$ ) was added to $19 \mu$ l of mastermix, containing final concentrations of $1.5 \mathrm{mM}$ of $\mathrm{Mg}^{2+}(2 \mu \mathrm{l}$ of $1 \mathrm{x}$ PCR buffer and $0.6 \mu \mathrm{l}$ of separate $\mathrm{MgCl}_{2}$ ), $0.2 \mathrm{mM}$ dNTP's each, $0.5 \mu \mathrm{M}$ forward and reverse primer and 1.0U of Taq polymerase. Primer sequences (Table 2) were selected based on antibiotic genes known from the literature to be associated with the MIC phenotypes of interest in this study. All PCR reactions were run for 30 cycles with a final extension of five minutes. Samples were analysed by electrophoresis with Tris-Borate EDTA (TBE), in 1.5\% agarose with ethidium bromide (final concentration $0.5 \mu \mathrm{g} / \mathrm{ml}$ ) at 100 volts and visualised on an Alpha Imager (Cell biosciences Heidelberg, Germany).

\section{Results}

The enterococci recovered from a variety of agrarian sources (Table 1) were tested for antibiotic resistance phenotypes as well as their pheromone-induced clumping ability, to identify a subgroup of isolates that were likely to undergo horizontal gene transfer by conjugation. A clumping reaction manifested as a large collection of densely packed immobile cells surrounded by planktonic cells (Fig. 1). Positive clumping reactions occurred within the same species as well as between members of different species e.g. ST01109 ${ }^{\text {Rif }}$ (E. faecium) cell-free supernatant induced clumping when added to 
Table 2 Primer sequences for antibiotic resistance genes

\begin{tabular}{|c|c|c|c|c|}
\hline \multicolumn{5}{|c|}{ List of primers used } \\
\hline Gene & Primer & Sequence $5^{\prime}$ to $3^{\prime}$ & $\begin{array}{l}\text { Product } \\
\text { Size }\end{array}$ & References \\
\hline \multirow[t]{2}{*}{ tetK } & tetK F & TTAGGTGAAGGGTTAGGTCC & 718 & [31] \\
\hline & tetK R & GCAAACTCATTCCAGAAGCA & & \\
\hline \multirow[t]{2}{*}{ tetL } & tetL $F$ & ATAAATTGTTTCGGGTCGGTAAT & 1077 & [32] \\
\hline & tetL $\mathrm{R}$ & AACCAGCCAACTAATGACAATGA & & \\
\hline \multirow[t]{2}{*}{ tetM } & tetM F & GTTAAATAGTGTTCTTGGAG & 657 & {$[31]$} \\
\hline & tetM R & CTAAGATATGGCTCTAACAA & & \\
\hline \multirow[t]{2}{*}{ tetO } & tetO F & GATGGCATACAGGCACAGAC & 614 & [33] \\
\hline & tetO R & CAATATCACCAGAGCAGGCT & & \\
\hline \multirow[t]{2}{*}{ tets } & tetS F & TGGAACGCCAGAGAGGTATT & 660 & [33] \\
\hline & tetS R & ACATAGACAAGCCGTTGACC & & \\
\hline \multirow[t]{2}{*}{ tetT } & tetT F & AAGGTTTATTATATAAAAGTG & 169 & [34] \\
\hline & tetT $\mathrm{R}$ & AGGTGTATCTATGATATTTAC & & \\
\hline \multirow[t]{2}{*}{ tetW } & tetW F & GAGAGCCTGCTATATGCCAGC & 168 & [33] \\
\hline & tetW R & GGGCGTATCCACAATGTTAAC & & \\
\hline \multirow[t]{2}{*}{ ErmB } & ermB F & AGGGTTGCTCTTGCACACTC & 119 & This study ${ }^{1}$ \\
\hline & ermB R & CTGTGGTATGGCGGGTAAGT & & \\
\hline \multirow[t]{2}{*}{$\operatorname{Van} A$} & $\operatorname{van} A F$ & CTACTCCCGCCTITTGGGTT & 109 & This study ${ }^{2}$ \\
\hline & $\operatorname{vanA} R$ & TTCACACCGAAGGATGAGCC & & \\
\hline
\end{tabular}

MF06036 (E. faecalis) (Table 3). Eleven isolates of E. faecalis and four isolates of E. faecium were selected based on clumping ability and antimicrobial resistance phenotype as having potential to transfer antibiotic resistance by conjugation.

\section{Clumping assay to identify potential donor and recipient enterococci}

The prospective ability to conjugate was demonstrated by clumping of potential donor cells in the presence of cell free supernatant from a potential recipient (Fig. 1). Of the isolates screened MW01105, MW02043 and ST01109 did not have the ability to clump under these conditions and were therefore designated as potential recipients. The remaining isolates were considered potential donor isolates as they could be induced to clump. We observed a number of reactions including some strains that gave a highly- specific clumping profile and only reacted to supernatant from one other strain e.g. MW02102 and ST02011 exhibited a single clumping reaction while others demonstrated the potential for promiscuity by reacting to supernatants from a number of strains e.g. MW03025 and MF04010 readily reacted to the pheromone of all the recipient isolates.

\section{Antibiotic resistance profiles of donor and recipient} enterococci

Of the isolates tested, most demonstrated at least two antibiotic resistance phenotypes (Table 4). MF06035 was highly resistant to five antibiotics and MF06036 was resistant to six antibiotics (Table 4). The isolates (MW01038-ST02011) appeared to show a typical susceptibility to vancomycin in broth microdilution assays. Additionally, ST02011 was highly resistant to kanamycin having an MIC of $2048 \mu \mathrm{g} / \mathrm{ml}$. MF06019 was highly resistant to erythromycin (x256 higher compared to ECOFF values (Table 4)) and kanamycin. MF04010 was one of two isolates that was highly resistant to tetracycline (x32 higher than the ECOFF values). MF06030 was resistant to tetracycline and highly resistant to kanamycin, and MF03061 was also resistant to tetracycline. MW01105 ${ }^{\text {Rif }}$ was highly resistant to streptomycin (at least four times more resistant than the other recipients) and is a highly resistant rifampicin mutant. MW02043 ${ }^{\text {Rif }}$ was highly resistant to kanamycin and was also a rifampicin resistant mutant. ST01109 ${ }^{\text {Rif }}$ was a highly resistant rifampicin mutant that was completely susceptible to all tested antibiotics.

\section{Successful horizontal transfer of antibiotic multi- resistance amongst enterococci}

Demonstration of phenotypic clumping ability successfully predicted the capture of horizontal gene transfer in three donor isolates. E. faecalis MW01105 ${ }^{\text {Rif }}$ received horizontal gene transfer from the three donors MF06036, MF04010 and MF06035 (all E. faecalis). These reactions produced transconjugants T1, T2 and T4 respectively. Transconjugant T1 gained resistance to four of the six antibiotics (vancomycin, erythromycin, trimethoprim and teicoplanin) from its donor MF06036. Transconjugant T2 gained resistance to tetracycline from its donor MF04010. Transconjugant $\mathrm{T} 4$ gained resistance to the same four antibiotics (vancomycin, erythromycin, trimethoprim and teicoplanin) as its donor MF06035 (Table 4). Additionally, an interspecies transfer event (transconjugant T3) was captured with E. faecium ST01109 ${ }^{\text {Rif }}$ receiving horizontal gene transfer from E. faecalis MF06036, gaining resistance to streptomycin and tetracycline only. Transfer efficiencies ranging from $10^{-1}$ to $10^{-3}$ were determined for transconjugants $\mathrm{T} 1$ and $\mathrm{T} 4$ and ranges of $10^{-4}$ to $10^{-5}$ for transconjugants T2 and T3. Several of the donor isolates readily reacted to the pheromone of all three recipient isolates (Table 3). However, despite MW02043 ${ }^{\text {Rif }}$ inducing clumping in $42 \%$ of the donor isolates, isolation of transconjugants was unsuccessful. Transconjugant $\mathrm{T} 1$ was subjected to daily propagation on TSB for 12 weeks and as an endpoint it still retained its' acquired vancomycin resistance (data not shown), demonstrating in one instance the preservation of acquired genes. 

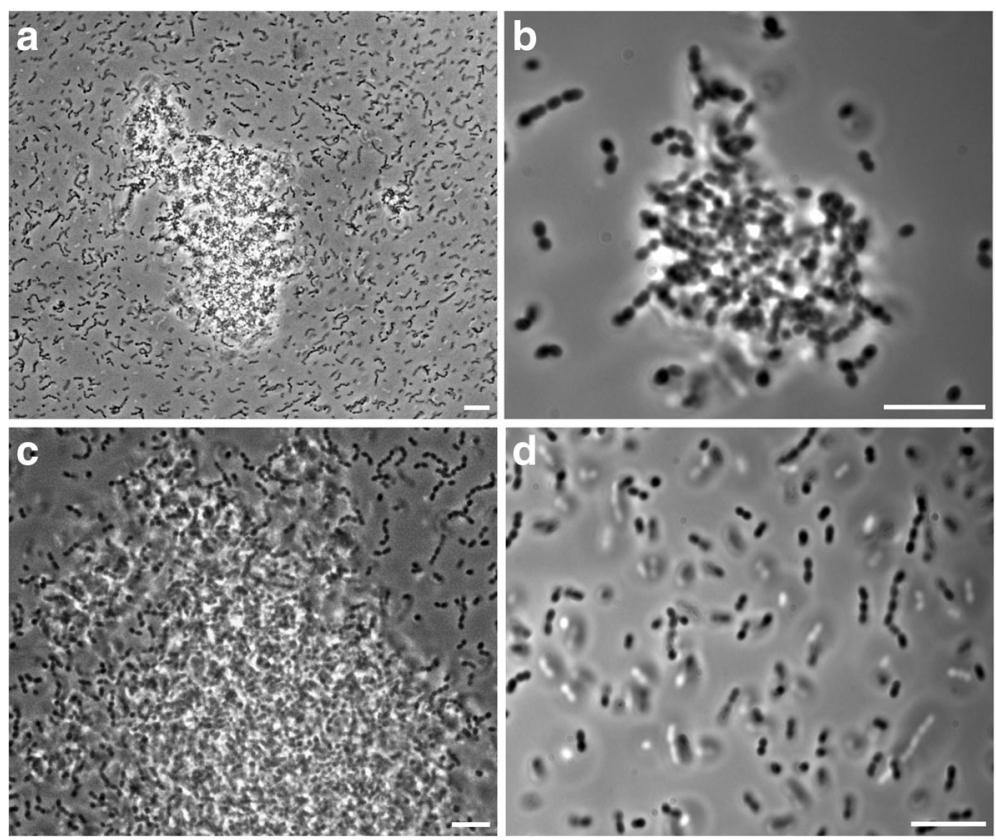

Fig. 1 Phenotypic clumping of enterococci examined with phase contrast microscopy. All potential donor isolates of enterococci were subjected to exposure of supernatant from each of the three pheromone producers for four hours in a 24 well microplate at $37^{\circ} \mathrm{C}$. (A) $20 \mathrm{x}$ micrograph of $E$. Faecalis MF06036 with the supernatant of E. Faecalis MW01105 Rif, (centre), the typical reaction observed when aggregation signalling is activated.

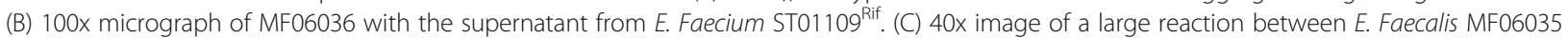
and the supernatant of MW01105 Rif. (D) 100x Negative clumping reaction of MF06036 supernatant added to MW01105 Rif. Scale bars represent ten microns

Table 3 Clumping of donor isolates by supernatant of recipient isolates

\begin{tabular}{llll}
\hline Recipients & & & \\
\hline & MW01105 & ST01109 & MW02043 \\
\hline Donor Isolates & & & ND \\
MF06035 & + & + & ND \\
MF06036 & + & ND & + \\
MW01038 & + & ND & ND \\
MW02102 & + & + & + \\
MW03020 & + & + & + \\
MW03025 & + & ND & + \\
MW03051 & + & + & ND \\
ST02011 & ND & + & + \\
MF06019 & + & + & + \\
MF04010 & + & + & + \\
MF06030 & + & + & ND \\
MW03061 & ND & & + \\
\hline
\end{tabular}

Positive clumping phenotypes presented when supernatant was added to potential donor isolates (Lab identifier numbers). MW01105, MW02043 and ST01109 induce clumping and therefore do not react to supernatants. MW01105 induces clumping in 9 isolates; ST01109 induces clumping in 8 isolates; and ST01109 induces clumping in 7 isolates. Donor isolates such as MW03025 and MF04010 can be induced to clump by all three supernatants. Other Donors such as ST02011 can only be induced to clump by one supernatant (ST01109). ND none detected
PCR detection of resistance genes among transconjugants and their donors

Phenotypically, antibiotic resistances were efficiently transferred among environmental enterococcal isolates. To confirm these transfer events, PCR was carried out to identify these genes in the donors and their transconjugants (Table 5). As vancomycin resistance transfer was observed phenotypically, the vanA gene was tested for in the recipient $\mathrm{MW} 01105^{\text {Rif }}$, its donors MF06036 and MF06035, and the transconjugants T1 and T4. The vanA gene was identified in the donors and the transconjugants but not in the recipient and there was a similar finding for the erythromycin resistance gene $\operatorname{erm} B$. The recipients MW01105 ${ }^{\text {Rif }}$ and ST01109 ${ }^{\text {Rif }}$, the donors MF04010 and MF06036 and the transconjugants were all investigated for the presence of seven tetracycline genes (tet $K$, tet $L$, tet $M$, tet $O$, tetS, tet $T$, tet $W)$. The tetracycline gene tet $L$ and tet $M$ were found in the donors with tet $M$ being transferred to both $\mathrm{T} 1$ and $\mathrm{T} 2$ with only tet $L$ being transferred to $\mathrm{T} 2$. None of these tetracycline genes were identified in the recipients.

\section{Discussion}

We set out to establish if environmental enterococci possessed antimicrobial resistance genes and if they were able to pass them on to other naturally isolated enterococci. In 
Table 4 Antibiotic resistance profiles of enterococcus isolates and transconjugants

\begin{tabular}{|c|c|c|c|c|c|c|c|}
\hline \multirow[t]{2}{*}{ Enterococcal isolates and transconjugants } & \multicolumn{7}{|c|}{$\mathrm{MIC}(\mu \mathrm{g} / \mathrm{ml})$ at $24 \mathrm{~h}$} \\
\hline & VA & E & SM & TET & TMP & TE & KAN \\
\hline E.faecalis MF06035 & $\mathrm{R}$ & $\mathrm{R}$ & $\mathrm{R}$ & $R$ & $\mathrm{R}$ & $\mathrm{R}$ & 64 \\
\hline E.faecalis MF06036 & $\mathrm{R}$ & $\mathrm{R}$ & $\mathrm{R}$ & $\mathrm{R}$ & $\mathrm{R}$ & $\mathrm{R}$ & 64 \\
\hline E.faecalis MW01038 & 4 & $<0.25$ & 256 & $<0.5$ & $\mathrm{R}$ & 0.5 & 256 \\
\hline E.faecalis MW02102 & 4 & $<0.25$ & 256 & $<0.5$ & $\mathrm{R}$ & 1 & 64 \\
\hline E.faecalis MW03020 & 4 & $<0.25$ & 256 & $\mathrm{R}$ & 0.25 & $<0.25$ & 64 \\
\hline E.faecalis MW03025 & $\mathrm{R}$ & $<0.25$ & 256 & 1 & 1 & $<0.25$ & 64 \\
\hline E.faecalis MW03051 & 4 & $<0.25$ & 256 & 1 & 0.5 & 1 & 64 \\
\hline Efaecalis ST02011 & 4 & $32^{R}$ & 128 & $<0.5$ & 0.25 & $<0.25$ & 1024 \\
\hline E.faecium MF06019 & 1 & $\mathrm{R}$ & 64 & $<0.5$ & 0.06 & $<0.25$ & $>1024^{\text {HLR }}$ \\
\hline Efaecalis MF04010 & 1 & $<0.25$ & $\mathrm{R}$ & $\mathrm{R}$ & 0.13 & $<0.25$ & 256 \\
\hline E.faecalis MF06030 & 0.5 & $<0.25$ & 64 & $R$ & 0.13 & $<0.25$ & $>1024^{\mathrm{HLR}}$ \\
\hline E.faecium MF03061 & 1 & 1 & 32 & $\mathrm{R}$ & 0.06 & $<0.25$ & 1024 \\
\hline E.faecalis MW01105 Rif & 1 & 0.5 & $\mathrm{R}$ & $<0.5$ & 0.13 & 2 & 128 \\
\hline E.faecalis MW02043 Rif & 0.5 & $<0.25$ & 32 & $<0.5$ & 0.06 & $<0.25$ & $>1024^{\text {HLR }}$ \\
\hline E.faecium ST01 109 Rif & 2 & $\mathrm{R}$ & 128 & $<0.5$ & 0.5 & $<0.25$ & 256 \\
\hline T1 & $\mathrm{R}$ & $\mathrm{R}$ & $\mathrm{R}$ & 2 & $\mathrm{R}$ & $\mathrm{R}$ & 64 \\
\hline $\mathrm{T} 2$ & 1 & $<0.25$ & $\mathrm{R}$ & $\mathrm{R}$ & 0.13 & 2 & 64 \\
\hline T3 & 1 & $<0.25$ & $\mathrm{R}$ & R & 0.5 & $<0.25$ & 128 \\
\hline T4 & $\mathrm{R}$ & $\mathrm{R}$ & $\mathrm{R}$ & $\mathrm{R}$ & $\mathrm{R}$ & $\mathrm{R}$ & 128 \\
\hline ECOFF & VA & $E$ & SM & TET & TMP & TE & KAN \\
\hline E.faecalis & 4 & 4 & 512 & 4 & 1 & 2 & ND \\
\hline E.faecium & 4 & 4 & 128 & 4 & ND & 2 & ND \\
\hline
\end{tabular}

VA vancomycin, E erythromycin, SM streptomycin, TET tetracycline, TMP trimethoprim, TE teicoplanin, KAN kanamycin. ECOFF Environmental cut-off [17]

$\mathrm{HLR}_{\text {, }}$ High level resistant*; ${ }^{\mathrm{R}}$, Resistant

Rif, Rifampicin resistant mutant; ND Not determined

Kanamycin resistance is $\geq 2000 \mu \mathrm{g} / \mathrm{ml}$ [35]

pheromone dependant conjugation the phenotypical presentation of conjugation compatibility for an enterococcal plasmid donor is a characteristic cellular clumping reaction when exposed to a potential recipient. All enterococci were screened for clumping phenotypes and antibiotic resistance phenotypes.

The enterococci (Table 1) consisted of a combination of E. faecalis and E. faecium from varied sources in an agrarian system. Three pheromone producing isolates were selected based on their clumping of the selected donor isolates and their susceptible antimicrobial resistance profiles $[22,23]$. In order to detect horizontal gene, transfer and capture transconjugants using antimicrobial selection, the recipient isolates required an antibiotic resistance that had universal susceptibility amongst the donor group. The group of potential donor isolates had both varied and prolific antimicrobial resistance phenotypes (Table 4) and Rifampicin resistance was chosen as it is caused by a point mutation rather than an acquired gene [24]. When comparing the donor isolates to ECOFF breakpoints (Table 4)

Table 5 Transferred antibiotic resistance genes identified by PCR

\begin{tabular}{|c|c|c|c|c|c|}
\hline Transconjugant & Donor & Recipient & Selection conditions $(\mu \mathrm{g} / \mathrm{ml})$ & Genes transferred & Efficiency \\
\hline $\mathrm{T1}$ & MF06036 & MW1 105 Rif & Vancomycin (10) + rifampicin (100) & vanA, ermB & $7.8 \times 10^{-3}$ \\
\hline $\mathrm{T} 2$ & MF04010 & MW1 105 Rif & Tetracycline (10) + rifampicin (100) & Tet M Tet L & $2.3 \times 10^{-5}$ \\
\hline T3 & MF06036 & ST01109 ${ }^{\text {Rif }}$ & Tetracycline (10) + rifampicin (100) & Tet M & $1.8 \times 10^{-4}$ \\
\hline T4 & MF06035 & MW1 105 Rif & Vancomycin (10) + rifampicin (100) & vanA. ermB & $1.22 \times 10^{-1}$ \\
\hline
\end{tabular}

Solid plate mating reactions that resulted in the isolation of transconjugants. Donors and recipients were conjugated together on TSA and plated on selection media. Successful reactions were subjected to PCR and their transfer efficiency was calculated 
it was clear that many of the resistance phenotypes were significantly higher than what is normally observed from the epidemiological data [17]. MF06035 and MF06036 both demonstrated high level resistance to several antibiotics including vancomycin $(256 \mu \mathrm{g} / \mathrm{ml}$ and $>512 \mu \mathrm{g} / \mathrm{ml}$ respectively) compared to lower ranges: $60-100 \mu \mathrm{g} / \mathrm{ml}$ as reported by others [25]. Close to $50 \%$ of the isolates were resistant to at least two antimicrobials. No isolate was resistant to all of the antibiotics tested; however higher numbers of the isolates tested showed resistance to kanamycin and tetracycline and overall resistance at the higher concentrations were exhibited by isolates against erythromycin, streptomycin and kanamycin (Table 4). These findings agree with previous reports of a high frequency of antibiotic resistant enterococci in farm animals [26].

Successful conjugation reactions resulted in the isolation of four transconjugants (T1-T4). MIC's carried out on the four transconjugants, highlighted all resistance phenotype transfers that occurred. Transconjugants 1 and 4 each had four resistance phenotypes transferred in one reaction which is rare as, at most, one or two resistance phenotype co-transfers have been reported [27]. With the growing concern that enterococci are a persistent nosocomial pathogen globally and their position as a highly competent reservoir for the transfer of serious virulence genes, this study demonstrates novel horizontal gene transfer events at high frequency.

The donor strain MF06036 was responsible for resistance transfer events resulting in different transconjugants (T1 and $\mathrm{T} 3$ ). Both conjugation reactions resulted in two different resistance transfer events and to our knowledge this is the first observation, of this kind, in enterococci isolated from an agrarian waterway ecosystem. This further demonstrates the broad range of transfer capability present within these enterococci. Transconjugant $\mathrm{T} 1$ retained its acquired vancomycin resistance, suggesting that pheromone responsive plasmids also code for maintenance and highly conserved replication systems [28] which supports their stability in transformed cells.

All transfer efficiencies in the generation of the transconjugants were within the ranges of the published literature $[20,29]$. Transfer of vancomycin and/or erythromycin resistance was observed with a frequency of $10^{-1}-10^{-3}$ obtained for donors isolated from poultry litter. In our hands the transfer frequency for tetracycline was only slightly lower $\left(10^{-4}-10^{-5}\right)$. However, Vignaroli et al. [27] showed frequencies of $10^{-6}-10^{-9}$ where, transfer occurred from donor strains isolated from animal faeces to a human E. faecium strain.

The resistant genes selected for in the current study (vancomycin, erythromycin and tetracycline) are coded on enterococcal mobile genetic elements and are of particular interest due to their association with nosocomial infections [12]. Transfer of antibiotic resistances from enterococci associated with food to those enterococci associated with the human gut has been reported [27] and $v a n A$ and ermB co-transfer from pig to human isolates has also been described [30]. In the current study MF06035, MF06036 and their transconjugants T1 and T4 tested positive for the $v a n A$ and ermB gene and MF04010, MF06036 and their transconjugants T2 and T3 carried the tetracycline genes tet $M$, tet $L$ in line with the frequent location of these determinants on the same mobile genetic element, mainly transposons, in Gram positive bacteria [28]. To our knowledge this is the first report of the transfer of antibiotic resistances genes from farm associated E. faecalis to water catchment associated E. faecium.

\section{Conclusions}

Within the environmental isolates examined, we see quite a diverse set of (potential) conjugation patterns. We have shown that multi-resistant organisms have greater conjugation potential than those isolates that exhibit a less resistant phenotype. The data suggested that this environment is a reservoir for strains that have the ability to conjugate and we have shown their ability to conjugate in vitro. Given the number of isolates investigated in this study, the potential for similar catchments to produce multiple antibiotic resistance strains is significant. In conclusion our findings show the importance of agrarian reservoirs of enterococci as sources of antibiotic resistance genes transmitted to human pathogens.

\section{Abbreviations \\ MIC: Minimum inhibitory concentration; TSA: Tryptone soy agar; TSB: Tryptone soya broth \\ Funding \\ The authors acknowledge support from Department of Employment and Learning (DEL). M. Conwell was the recipient of a DEL funded PhD \\ studentship and $V$. Daniels was the recipient of an Irish EPA studentship.}

\section{Availability of data and materials}

The datasets used and/or analysed during the current study are available from the corresponding author on reasonable request.

\section{Authors' contributions}

MC, PJN and JSGD designed the study. VD was responsible for the isolation and characterisation of the environmental isolates. $\mathrm{MC}$ was responsible for microbiology, molecular techniques and microscopy. MC, PJN and JSGD wrote and revised the manuscript. All authors read and approved the last version of the manuscript.

\section{Authors' information}

Not applicable.

Competing interests

The authors declare that they have no competing interests.

Consent for publication

Not applicable.

Ethics approval and content to participate

Not applicable. 
Received: 9 August 2016 Accepted: 9 January 2017

\section{Published online: 18 January 2017}

\section{References}

1. Van Tyne D, Gilmore MS. Friend turned foe: evolution of enterococcal virulence and antibiotic resistance. Ann Rev Microbiol. 2014;68:337-56. doi: 10.1146/annurev-micro-091213-113003.

2. Domig KJ, Mayer HK, Kneifel W. Methods used for the isolation, enumeration, characterisation and identification of Enterococcus spp. 2. Pheno- and genotypic criteria. Int J Food Microbiol. 2003;88:165-88.

3. Byappanahalli MN, Nevers MB, Korajkic A, Staley ZR, Harwood VJ. Enterococci in the environment. Microbiol Mol Biol Rev. 2012;76:685-706. doi:10.1128/MMBR.00023-12.

4. Aarestrup FM, McNicholas PM. Incidence of high-level evernimicin resistance in Enterococcus faecium among food animals and humans. Antimicrob Agents Chemother. 2002;46:3088-90.

5. Cabelli VJ. Health effects criteria for marine recreational waters. Research Triangle Park: U.S. Environmental Protection Agency; 1983.

6. Di Cesare A, Pasquaroli S, Vignaroli C, Paroncini P, Luna GM, Manso E, Biavasco F. The marine environment as a reservoir of enterococci carrying resistance and virulence genes strongly associated with clinical strains Environ Microbiol Rep. 2014:6:184-90. doi:10.1111/1758-2229.12125.

7. EPA 2012. Integrated water quality report Monaghan and Louth: Antimicrobials in agriculture and the environment: reducing unnecessary use and waste. http://www.epa.ie/pubs/reports/water/waterqua/iwqmolou/ IWO 2012 Monaghan Louth.pdf. Accessed 20 June 2016.

8. Review on Antimicrobial Resistance Report 2015 'Antimicrobials in agriculture and the environment: reducing unnecessary use and waste. Wellcome Trust. https://amr-review.org/sites/default/files/ Antimicrobials\%20in\%20agriculture\%20and\%20the\%20environment\%20\%20Reducing\%20unnecessary\%20use\%20and\%20waste.pdf. Accessed 20 June 2016.

9. Gilmore MS, Lebreton F, van Schaik W. Genomic transition of enterococci from gut commensals to leading causes of multidrug-resistant hospital infection in the antibiotic era. Curr Opin Microbiol. 2013;16:10-6. doi:10. 1016/j.mib.2013.01.006.

10. Clewell DB. Movable genetic elements and antibiotic resistance in enterococci. Eur J Clin Microbiol Infect Dis. 1990;9:90-102.

11. Manson JM, Hancock LE, Gilmore MS. Mechanism of chromosomal transfer of Enterococcus faecalis pathogenicity island, capsule, antimicrobial resistance, and other traits. Proc Natl Acad Sci U S A. 2010;107:12269-74 doi:10.1073/pnas.1000139107.

12. Guzman Prieto AM, van Schaik W, Rogers MR, Coque TM, Baquero F, Corander J, Willems RJ. Global emergence and dissemination of enterococci as nosocomial pathogens: attack of the clones? Front Microbiol. 2016;7:788. doi:10.3389/fmicb.2016.00788

13. Cafini F, le Nguyen TT, Higashide M, Román F, Prieto J, Morikawa K. Horizontal gene transmission of the cfr gene to MRSA and Enterococcus: role of Staphylococcus epidermidis as a reservoir and alternative pathway for the spread of linezolid resistance. J Antimicrob Chemother. 2016;71:58792. doi:10.1093/jac/dkv391.

14. Daniels V. PhD Thesis: antibiotic resistant bacteria in Irish waters: molecular epidemiology and hydrological control. University of Ulster; 2011. Retrieved from http://ethos.bl.uk/OrderDetails.do?uin=uk.bl.ethos.551508. Assessed 20 June 2016.

15. Kühn I, Iversen A, Burman LG, Olsson-Liljequist B, Franklin A, Finn M, Aarestrup F, Seyfarth AM, Blanch AR, Taylor H, Caplin J, Moreno MA, Dominguez L, Möllby R. Epidemiology and ecology of enterococci, with special reference to antibiotic resistant strains, in animals, humans and the environment. Example of an ongoing project within the European research programme. Int J Antimicrob Agents. 2000;14:337-42.

16. Ahmed W, Neller R, Katouli M. Host species-specific metabolic fingerprint database for enterococci and Escherichia coli and its application to identify sources of fecal contamination in surface waters. Appl Environ Microbiol. 2005;71:4461-8.

17. European Committee on Antimicrobial Susceptibility Testing. Data from the EUCAST MIC distribution website. https://mic.eucast.org/Eucast2/. Accessed 27 Sept 2016

18. Wiegand I, Hilpert K, Hancock RE. Agar and broth dilution methods to determine the minimal inhibitory concentration (MIC) of antimicrobial substances. Nat Protoc. 2008;3:163-75. doi:10.1038/nprot.2007.521.
19. Jahan M, Krause DO, Holley RA. Antimicrobial resistance of Enterococcus species from meat and fermented meat products isolated by a PCR-based rapid screening method. Int J Food Microbiol. 2013;15:89-95. doi:10.1016/j. ijfoodmicro.2013.02.017.

20. Cook L, Barnes A, Dunny G. Biofilm growth alters regulation of conjugation by a bacterial pheromone. Mol Microbiol. 2011;81(6):1499-510.

21. Tsuchizaki N, Ishikawa J, Hotta K. Colony PCR for rapid detection of antibiotic resistance genes in MRSA and enterococci. Jpn J Antibiot. 2000; 53:422-9.

22. Palmer KL, Kos VN, Gilmore MS. Horizontal gene transfer and the genomics of enterococcal antibiotic resistance. Curr Opin Microbiol. 2010;13:632-9. doi:10.1016/j.mib.2010.08.004

23. Dunny GM. Enterococcal sex pheromones: signaling, social behavior, and evolution. Ann Rev Genet. 2013;47:457-82. doi:10.1146/annurev-genet$111212-133449$

24. Enne VI, Delsol AA, Roe JM, Bennett PM. Rifampicin resistance and its fitness cost in Enterococcus faecium. J Antimicrob Chemother. 2004:53:203-7.

25. Courvalin P. Vancomycin resistance in gram-positive cocci. Clin Infect Dis. 2006;42 Suppl 1:S25-34.

26. Donabedian SM, Thal LA, Hershberger E, Perri MB, Chow JW, Bartlett P, Jones R, Joyce K, Rossiter S, Gay K, Johnson J, Mackinson C, Debess E, Madden J, Angulo F, Zervos MJ. Molecular characterization of gentamicinresistant Enterococci in the United States: evidence of spread from animals to humans through food. J Clin Microbiol. 2003;41:1109-13.

27. Vignaroli C, Zandri G, Aquilanti L, Pasquaroli S, Biavasco F. Multidrugresistant enterococci in animal meat and faeces and co-transfer of resistance from an Enterococcus durans to a human Enterococcus faecium. Curr Microbiol. 2011;62:1438-47. doi:10.1007/s00284-011-9880-x.

28. Werner G, Coque TM, Franz CM, Grohmann E, Hegstad K, Jensen L, van Schaik W, Weaver K. Antibiotic resistant enterococci-tales of a drug resistance gene trafficker. Int J Med Microbiol. 2013;303:360-79. doi:10.1016/ j.jimm.2013.03.001.

29. Huys G, D'Haene K, Collard JM, Swings J. Prevalence and molecular characterization of tetracycline resistance in Enterococcus isolates from food. Appl Environ Microbiol. 2004;70:1555-62.

30. Moubareck C, Bourgeois N, Courvalin P, Doucet-Populaire F. Multiple antibiotic resistance gene transfers from animal to human enterococci in the digestive tract of gnotobiotic mice. Antimicrob Agents Chemother. 2003:47:2993-6.

31. Aarestrup FM, Agerso Y, Gerner-Smidt P, Madsen M, Jensen LB. Comparison of antimicrobial resistance phenotypes and resistance genes in Enterococcus faecalis and Enterococcus faecium from humans in the community, broilers, and pigs in Denmark. Diagn Microbiol Infect Dis. 2000; 37:127-37.

32. Trzcinski K, Cooper BS, Hryniewicz W, Dowson CG. Expression of resistance to tetracyclines in strains of methicillin-resistant Staphylococcus aureus. J Antimicrob Chemother. 2000;45:763-70.

33. Choi JM, Woo GJ. Transfer of tetracycline resistance genes with aggregation substance in food-borne Enterococcus faecalis. Curr Microbiol. 2015;70:47684. doi:10.1007/s00284-014-0742-1.

34. Aminov Rl, Garrigues-Jeanjean N, Mackie RI. Molecular ecology of tetracycline resistance: development and validation of primers for detection of tetracycline resistance genes encoding ribosomal protection proteins. Appl Environ Microbiol. 2001;67:22-32.

35. Leclercq R, Dutka-Malen S, Brisson-Noël A, Molinas C, Derlot E, Arthur M, Duval J, Courvalin P. Resistance of enterococci to aminoglycosides and glycopeptides. Clin Infect Dis. 1992;15:495-501. doi:10.1093/clind/15.3.495. 